Lee KH, Ryu SB, Lee MC, Park CS, Juhng SW, Choi C. Primary large cell neuroendocrine carcinoma of the urinary bladder. Pathol Int. 2006;56:688-93.

4. Li Y, Outman JE, Mathur SC. Carcinosarcoma with a large cell neuroendocrine epithelial component: First report of an unusual biphasic tumour of the urinary bladder. J Clin Pathol. 2004;57:318-20.

5. Hailemariam S, Gaspert A, Komminoth P, Tamboli P, Amin M. Primary, pure, large-cell neuroendocrine carcinoma of the urinary bladder. Mod Pathol. 1998;11:1016-20.

6. Evans AJ, Al-Maghrabi J, Tsihlias J, Lajoie G, Sweet JM, Chapman WB. Primary large cell neuroendocrine carcinoma of the urinary bladder. Arch Pathol Lab Med. 2002;126:1229-32.
P. Navarro Medina ${ }^{a, *}$, C. Camacho García ${ }^{b}$, A. Blanco Diez ${ }^{a}$, E. Barroso Deyne ${ }^{a}$, J. Armas Molina ${ }^{a}$, J.L. Artiles Hernández ${ }^{a}$ y N. Chesa Ponce ${ }^{a}$

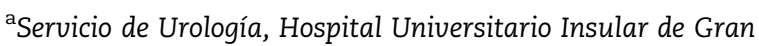
Canaria, Gran Canaria, España

${ }^{\mathrm{b}}$ Servicio de Anatomía Patológica, Hospital Universitario Insular de Gran Canaria, Gran Canaria, España

*Autor para correspondencia.

Correo electrónico: patricionm@terra.es (P. Navarro Medina).

\title{
Insuficiencia renal aguda obstructiva gestacional tras reimplante ureteral: a propósito de un caso
}

\section{Ureteral reimplantation and gestational acute renal failure: a case report}

\section{Sr. Director:}

Presentamos el caso de una mujer de 36 años, primigesta de 29 semanas, que consultó en el servicio de Urgencias de nuestro centro por dolor lumbar derecho irradiado a hipogastrio de 1 mes de evolución, junto con reciente aparición de edemas en miembros inferiores y marcada disminución de la diuresis.

En Urgencias las constantes eran normales, presentaba molestias a la palpación bimanual en ambas fosas renales y leves edemas con fóvea en miembros inferiores. La exploración ginecológica completa y ecografía transvaginal no mostraron hallazgos patológicos. El sedimento urinario era anodino y en analítica sanguínea destacaba una creatinina de $3,9 \mathrm{mg} / \mathrm{dl}$ y urea de $66 \mathrm{mg} / \mathrm{dl}$ (creatinina basal previa: 0,9 mg/dl). Se solicitó entonces, ecografía abdominal que objetivó ureteropielocaliectasia grado III bilateral, sin poder determinar la causa obstructiva. Con el diagnóstico de insuficiencia renal aguda obstructiva se procedió al ingreso hospitalario de la paciente. Al preguntar a la paciente por antecedentes urológicos refirió haber sido intervenida por reflujo vesicoureteral a los 3 años de edad mediante ureteroneocistostomía bilateral según técnica de Politano-Leadbetter, habiendo permanecido asintomática hasta este momento. En las primeras $48 \mathrm{~h}$ del ingreso continuó el deterioro progresivo de la función renal hasta cifras de creatinina de $4,9 \mathrm{mg} / \mathrm{dl}$ por lo que se decidió colocar de forma urgente nefrostomía percutánea derecha. Tras la derivación renal se produjo una poliuria desobstructiva, desapareció el dolor en el flanco derecho y los edemas, mejorando la función renal en las siguientes $72 \mathrm{~h}$ (creatinina: 1,1 mg/dl y urea: $32 \mathrm{mg} / \mathrm{dl}$ ).

Para completar el estudio se solicitó una resonancia magnética nuclear, donde se observa dilatación calicial leve en riñón derecho con catéter de nefrostomía sin complica- ciones en su trayecto y dilatación ureteropielocalicial izquierda grado III hasta su extremo más distal sin defectos de repleción en su interior, no llegando a identificar la zona de unión a nivel del trígono vesical; en pelvis menor se identifica el feto en posición cefálica, encajado, que condiciona efecto masa sobre vejiga. No se aprecian otras masas intrapélvicas ni otros hallazgos (figs. 1 y 2).

Se procedió entonces a colocar de forma programada nefrostomía percutánea izquierda sin incidencias. Desde entonces permaneció en domicilio presentando como incidencias dos infecciones urinarias sintomáticas por E. coli diagnosticadas por urinocultivo y tratadas según antibiograma.

A las 36 semanas de gestación los obstetras decidieron realizar cesárea electiva naciendo un varón sano de $2850 \mathrm{~g}$ con Apgar 9/9. Al 6. día postoperatorio fue dada de alta sin complicaciones.

A los 10 días del parto, realizamos a la paciente pielografía descendente bilateral por nefrostomía objetivando paso de contraste a vejiga, por lo que se cerraron ambas nefrostomías y se realizó control de diuresis domiciliario. Tras $48 \mathrm{~h}$ se reevaluó a la paciente que permanecía asintomática, con diuresis superiores a $2.000 \mathrm{ml} / \mathrm{d}$, creatinina de $0,84 \mathrm{mg} / \mathrm{dl} \mathrm{y}$ ecografía renal bilateral con ureteropielocaliectasia grado I en riñón derecho sin ectasia en el riñón izquierdo, por lo que se procedió a retirar las nefrostomías. A los 4 meses se realizó un nuevo control en el que presentó creatinina de $0,98 \mathrm{mg} / \mathrm{dl}$, ecografía renal bilateral sin evidencia de ectasia de vía y sedimento urinario anodino. Refiere que durante este tiempo se ha encontrado asintomática.

Entre el 40 y el 70\% de las mujeres embarazadas presentan algún grado de dilatación asintomática de la pelvis renal y los uréteres a nivel de la cresta ilíaca ${ }^{1}$. Esta dilatación se desarrolla durante el segundo trimestre del embarazo, 


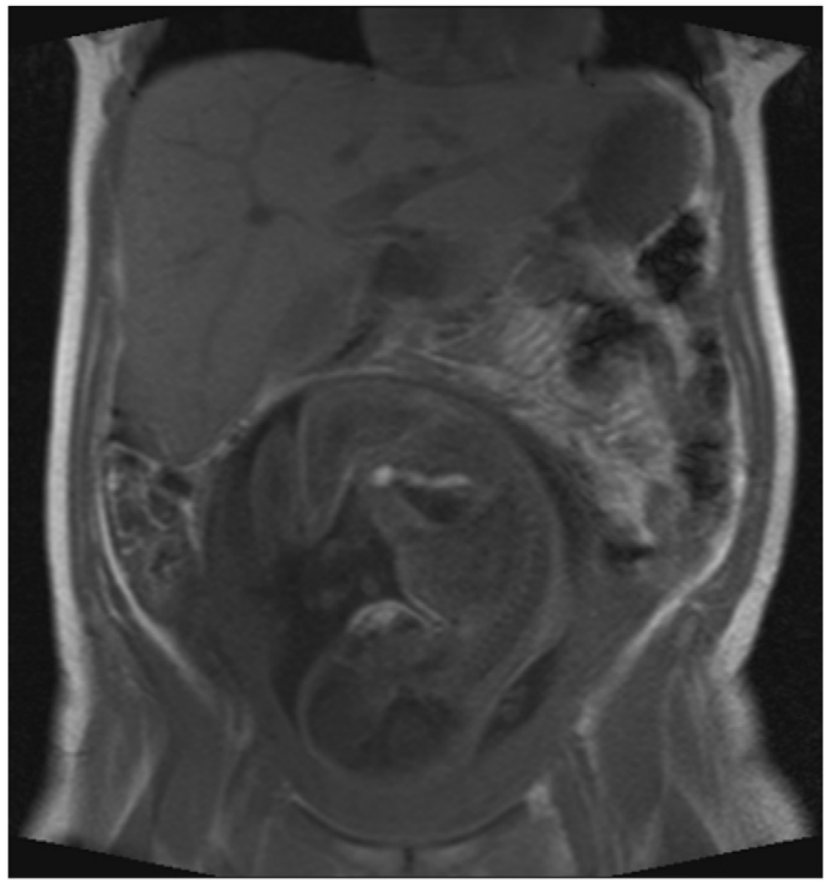

Figura 1 - Ureteropielocaliectasia izquierda por compresión ureteral.

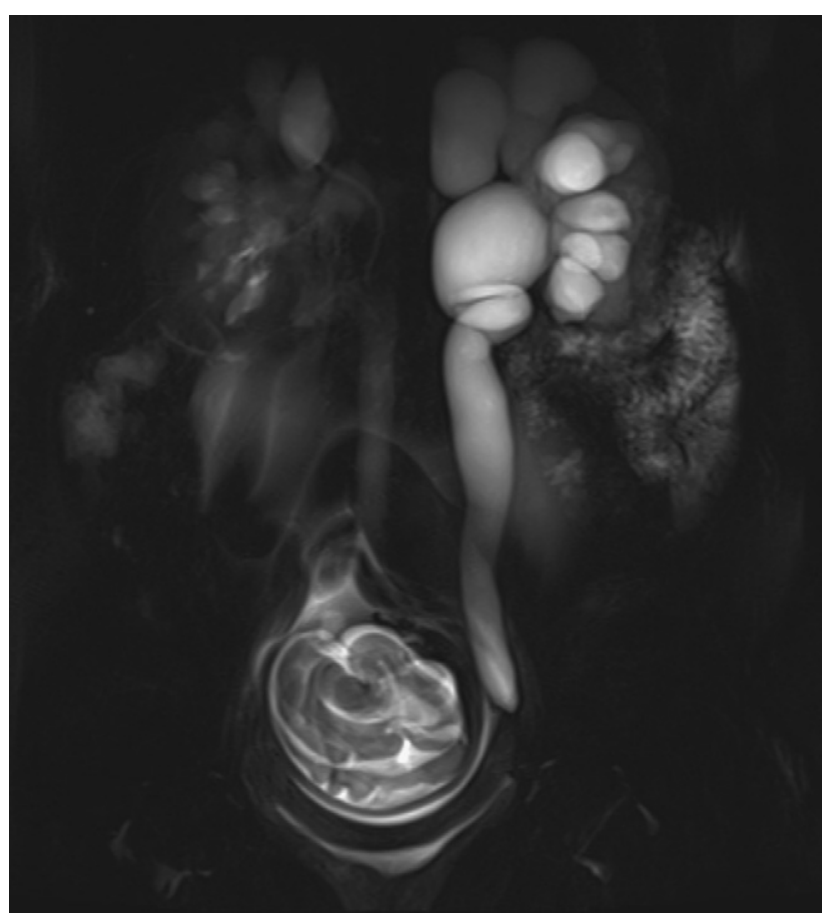

Figura 2 - Posición fetal a las 29 semanas.

llegando a ser máxima durante el tercer trimestre y revirtiendo a la normalidad a las pocas semanas tras el parto. Este fenómeno se debe a la relajación del músculo liso por la progesterona y al crecimiento uterino que comprime los uréteres, a nivel de la cresta iliaca ${ }^{1-4}$.

La dilatación ureteral es más frecuente en el lado derecho (76\% en lado derecho y $35 \%$ bilateral $)^{1}$. Estas diferencias se deben a la posición de los vasos iliacos en relación con los uréteres, ya que la vena ovárica derecha cruza al uréter derecho a nivel de la cresta ilíaca y drena en la vena cava inferior mientras que la vena ovárica izquierda es paralela al uréter y drena en la vena renal izquierda. También puede atribuirse la menor frecuencia de dilatación izquierda a la protección que ofrece el colon sigmoide, que es anterior al uréter.

Si bien esta situación de hidronefrosis es, frecuente, en la mayoría de las ocasiones, asintomática y no precisa de ningún tipo de tratamiento, la insuficiencia renal aguda durante el embarazo es muy infrecuente, ocurriendo sólo en 1 de cada 10.000 embarazos ${ }^{1,2,4}$. Habitualmente, se asocia con aborto séptico, preeclampsia, o hemorragia uterina por placenta previa o abruptio placentae. Sin embargo la insuficiencia renal aguda debido a obstrucción ureteral bilateral por el crecimiento uterino durante el embarazo es extremadamente más infrecuente. Hasta la fecha, solo 24 casos han sido reportados ${ }^{1-3,5}$. Esta situación puede causar dolor lumbar severo y persistente, frecuentes infecciones del tracto urinario, hipertensión e incluso deterioro de la función renal como en nuestro caso.

Hay factores de riesgo reconocidos para padecer uropatía obstructiva bilateral como embarazo gemelar, polihidramnios, riñón único, baja complianza de la pared abdominal y primiparidad $^{1-5}$. Estos factores de riesgo han sido bien documentados en la literatura publicada hasta la fecha. Sin embargo entre ellos no se incluye la cirugía urológica previa ni el reimplante ureteral como factor de riesgo ${ }^{3,5,6}$. Ya en 1984 fue descrito un caso tras reimplante ureteral $^{3}$ y en 1995 se publicó una serie de mujeres con reimplate ureteral en la que se describía una mayor incidencia de insuficiencia renal obstructiva (5\%) durante el embarazo en estas pacientes respecto a la población general ${ }^{6}$. Posteriormente otros autores han llegado a la misma conclusión ${ }^{5}$.

La obstrucción ureteral durante el embarazo en mujeres que han sido previamente sometidas a reimplante ureteral está descrita como un fenómeno transitorio ${ }^{3,5}$. Se postula que el reimplante es permeable de manera suficiente y compensada cuando la paciente no está embarazada, sin embargo, su funcionamiento se ve comprometido durante la gestación cuando el tracto urinario es afectado por los cambios hormonales y mecánicos asociados ${ }^{5}$. Durante la gestación normal, la vejiga es desplazada anterior y superiormente por el crecimiento del útero. Conforme el embarazo progresa, la vejiga se recoloca en posición intraabdominal lo que condiciona la obstrucción ureteral en los pacientes sometidos a ureteroneocistostomía según técnica de Politano-Leadbetter por el llamado «síndrome de reimplantación ureteral alta». Esta situación se produce al estar la parte distal del uréter reimplantada en la porción móvil de la vejiga y por tanto es propensa al acodamiento y obstrucción durante el desplazamiento vesical en el embarazo ${ }^{5}$. Otra posible explicación es que la fibrosis causada por la cirugía ureteral altera el peristaltismo en la porción más distal del uréter, condicionando así la obstrucción.

Con nuestra paciente son 7 los casos descritos en la literatura y es de destacar que en todos ellos el reimplante ureteral fue del tipo Politano-Leadbetter ${ }^{3,5,6}$.

La clínica se manifiesta durante el segundo trimestre del embarazo y consiste en insuficiencia renal, hipertensión, edemas y oliguria. Sin embargo, algunas veces puede complicarse con pielonefritis aguda severa ${ }^{1-9}$. 
Varias modalidades terapéuticas han sido propuestas en la literatura para solucionar la obstrucción y el fracaso renal. Posicionar a la paciente en decúbito lateral puede mejorar la descompresión del uréter afectado; asimismo, una amniotomía podría hacerse para aliviar la obstrucción y mejorar la función renal, sobre todo en caso de polihidramnios. Pero actualmente, la colocación de nefrostomías percutáneas o catéteres ureterales (si el reimplante lo permite) con control ecográfico se ha convertido en el tratamiento de elección en estos casos. Sin embargo, la resolución definitiva del cuadro se obtiene con la finalización del embarazo que debe realizarse en cuanto el feto sea suficientemente maduro ${ }^{1-5}$.

Para evitar la obstrucción en embarazos posteriores puede realizarse un nuevo reimplante ureteral, con una disección meticulosa del uréter distal que se reinsertará a través de una tunelización submucosa más caudal a nivel de la base de la vejiga ${ }^{5}$.

Por tanto aquellas mujeres con una historia previa de reimplantación ureteral bilateral según técnica de PolitanoLeadbetter tienen incrementado el riesgo de obstrucción ureteral, a nivel de la unión urétero-vesical y deterioro de la función renal secundario durante el embarazo. Por ello deben ser vigiladas desde el punto de vista urológico durante el embarazo, particularmente si presentan dolor lumbar, disminución de la diuresis y/o hipertensión. La detección precoz de esta entidad es esencial para proporcionar una adecuada derivación urinaria provisional, evitando posteriores complicaciones mayores tanto para la madre como para el feto.

B I B L I O G R A F Í A

1. Jena M, Mitch WE. Rapidly reversible acute renal failure from ureteral obstruction in pregnancy. American Journal of Kidney Diseases. 1996;28:457-60.
2. Brandes JC, Fritsche C. Obstructive acute renal failure by a gravid uterus: a case report and review. American Journal of Kidney Diseases. 1991;18:398-401.

3. Laverson PL, Hankins GD, Quirk Jr JG. Ureteral obstruction during pregnancy. The Journal of Urology. 1984;13:327-9.

4. Bennett AH, Adler S. Bilateral ureteral obstruction causing anuria secondary to pregnancy. Urology. 1982;20:631-3.

5. Mor Y, Leibovitch I, Fridmans A, Farkas A, Jonas P, Ramon J. Late post-reimplantation ureteral obstruction during pregnancy: a transient phenomenon? The Journal of Urology. 2003;170: 845-8.

6. Mansfield JT, Snow BW, Cartwright PC, Wadsworth K. Complications of pregnancy in women after childhood reimplantation for vesicoureteral reflux: an update with 25 years of followup. The Journal of Urology. 1995;154:787-90.

7. Austenfeld MS, Snow BW. Complications of pregnancy in women after reimplatation for vesicoureteral reflux. The Journal of Urology. 1988;140:1103-6.

8. Mor Y, Leibovitch I, Zalts R, Lotan D, Jonas P, Ramon J. Analysis of the long-term outcome of surgically corrected vesicoureteric reflux. BJU International. 2003;92:97-100.

9. Hollowel JG. Outcomes of pregnancy in women whith a history of vesico-ureteric reflux. BJU International. 2008;102: $780-4$.

G. Morales Solchaga*, A. Soto Poveda, G. García Fadrique y J.F. Jiménez Cruz

Servicio de Urología, Hospital Universitario La Fe de Valencia, Valencia, España

*Autor para correspondencia. Correo electrónico: gonzalo.uro@gmail.com (G. Morales Solchaga).

\section{Tumor neuroendocrino primario del riñón Primary neuroendocrine tumor of the kidney}

\section{Sr. Director:}

Presentamos el caso de un paciente con pérdida de peso y una masa en el flanco izquierdo con varios meses de evolución. En la TAC abdominal se podía ver un quiste complejo del riñón de $16 \mathrm{~cm}$ y un nódulo hepático solitario (fig. 1). Los análisis de sangre y los marcadores tumorales estaban dentro de la normalidad.

La nefrectomía radical izquierda reveló una neoplasia de $16 \mathrm{~cm}$ con necrosis y hemorragia central, delimitada por un tejido de $2 \mathrm{~cm}$ de aspecto blanquecino. La histología reveló un carcinoma de patrón cordonal sin atipias celulares o pleomorfismo celular y el índice mitótico mínimo. La neoplasia, confinada por la cápsula renal, tenía infiltración venosa microscópica y un nódulo linfático hilar metastatizado, pero ninguna invasión vascular mayor. La marcación inmunohistoquímica fue positiva para CD57/Leu7, NSE, sinaptofisina y cromogranina, demostrando que se trataba de un tumor neuroendocrino bien diferenciado (fig. 2).

En el postoperatorio se realizaron examen endoscópico gastrointestinal, TAC torácica y marcadores neuroendocrinos (5-HIAA y gastrina), que resultaron normales. En la 